\title{
HUBUNGAN TINGKAT PENGETAHUAN TENTANG DISMENOREA DENGAN PERILAKU PENANGANAN DISMENOREA PADA MAHASISWI FK UMI MAKASSARANGKATAN 2013
}

\author{
Rasfayanah \\ *Bagian Biokimia Fakultas Kedokteran Universitas Muslim Indonesia
}

\begin{abstract}
Abstrak: Dismenorea merupakan nyeri perut bagian bawah yang terkadang rasa nyeri tersebut meluas hingga ke pinggang, punggung bagian bawah dan paha. Angka kejadian dismenorea di dunia sangat besar. Rata-rata lebih dari 50\% perempuan di setiap dunia mengalaminya. Dari hasil penelitian, di Amerika persentase kejadian dismenorea sekitar $60 \%$, Swedia 72\% dan di Indonesia 55\%. Wanita di Indonesia yang mengalami dismenorea lebih banyak mengatasinya dengan mengkonsumsi obat penghilang rasa nyeri yang beredar di pasaran. Sebagian masyarakat juga beranggapan bahwa nyeri ini akan hilang setelah wanita menikah, sehingga mereka membiarkan gangguan tersebut. Tujuan penelitian ini adalah untuk mengetahui tingkat pengetahuan mahasiswi Fakultas Kedokteran UMI Makassar angkatan 2013 tentang dismenorea dengan perilaku penanganan disemenorea. Penelitian ini merupakan penelitian yang menggunakan desain penelitian analitik dengan teknik pengambilan sampel menggunakan simple random sampling. Jumlah sampel sebanyak 96 orang. Pengolahan data dilakukan dengan menggunakan program Microsoft Excel 2010 dan SPSS versi 18.0. Data yang diolah kemudian disajikan dalam bentuk tabel dan dijelaskan dalam bentuk narasi (uraian) untuk memperjelas hubungan antara variabel dependen dan variabel independen. Hasil penelitian tingkat pengetahuan mahasiswi mengenai dismenorea sebanyak 33 responden $(34,4 \%)$ memiliki tingkat pengetahuan yang baik, sebanyak 31 responden $(32,3 \%)$ yang memiliki kategori cukup, dan sebanyak 32 responden (33,3\%) memiliki kategori kurang. Perilaku penanganan dismenorea sebanyak 75 responden $(21,246 \%)$ melakukan pemijatan untuk menangani dismenorea yang dirasakan secara mandiri dan sebanyak 63 responden (65,6 \%) telah melakukan perilaku yang sesuai untuk menangani dismenorea. Hasil penelitian ini menunjukkan bahwa ada hubungan tingkat pengetahuan tentang dismenorea dengan perilaku penanganan dismenorea pada mahasiswi Fakultas Kedokteran Universitas Muslim Indonesia Angkatan 2013.
\end{abstract}

Kata Kunci: dismenorea, tingkat pengetahuan, perilaku penanganan, Mahasiswi Fk Umi Makassar Angkatan 2013 


\section{PENDAHULUAN}

Dismenorea merupakan nyeri perut bagian bawah yang terkadang rasa nyeri tersebut meluas hingga ke pinggang, punggung bagian bawah dan paha. ${ }^{1}$ Angka kejadian dismenorea di dunia sangat besar. Rata-rata lebih dari 50\% perempuan di setiap dunia mengalaminya. Dari hasil penelitian, di Amerika persentase kejadian dismenorea sekitar $60 \%$, Swedia $72 \%$ dan di Indonesia 55\%. Penelitian di Amerika Serikat menyebutkan bahwa dismenorea dialami oleh $30 \%-50 \%$ wanita usia reproduksi dan $10 \%$ $15 \%$ diantaranya kehilangan kesempatan kerja, mengganggu kegiatan belajar disekolah dan kehidupan keluarga. Begitu pula angka kejadian dismenorea di Indonesia cukup tinggi, namun yang berobat ke pelayanan kesehatan sangatlah sedikit, yaitu hanya $1 \%$ $-2 \% .^{2}$

Wanita di Indonesia yang mengalami dismenorea lebih banyak mengatasinya dengan mengkonsumsi obat penghilang rasa nyeri yang beredar di pasaran. Sebagian masyarakatjuga beranggapan bahwa nyeri ini akan hilang setelah wanita menikah, sehingga mereka membiarkan gangguan tersebut. ${ }^{3}$

Dismenorea adalah nyeri saat haid yang terasa di perut bagian bawah dan muncul sebelum, selama atau setelah menstruasi. Dismenorea timbul akibat kontraksi disritmik lapisan miometrium yang menampilkan satu atau lebih gejala mulai dari nyeri ringan hingga berat pada perut bagian bawah, daerah pantat dan sisi medial paha. ${ }^{1}$ Dismenorea dibagi menjadi dua berdasarkan penyebabnya yaitu dismenorea primer dan sekunder. Dismenorea primer adalah sensasi nyeri selama menstruasi, tetapi tidak berkaitan dengan penyebab fisik yang nyata. Sedangkan dismenorea sekunder adalah sensasi nyeri selama menstruasi dan mempunyai patologi panggul yang nyata. ${ }^{6}$

Dismenorea dibagi menjadi tiga tingkat keparahan, yaitu:

a. Dismenorea ringan

Seseorang akan mengalami nyeri atau nyeri masih dapat ditolerir karena masih berada pada ambang rangsang, berlangsung beberapa saat dan dapat melanjutkan pekerjaan sehari-hari. Dismenorea ringan terdapat dalam skala nyeri dengan tingkatan 1-4. ${ }^{7}$

b. Dismenorea sedang

Seseorang mulai merespon nyerinya dengan merintih dan menekannekan bagian yang nyeri, diperlukan obat penghilang rasa sakit tanpa perlu meninggalkan pekerjaannya. Dismenorea sedang terdapat pada skala nyeri dengan tingkatan 5-6. ${ }^{7}$

\section{c. Dismenorea berat}

Seseorang mengeluh karena adanya rasa terbakar dan ada kemungkinan seseorang tidak mampu lagi melakukan pekerjaan biasa dan perlu istirahat beberapa hari dapat disertai sakit kepala, migraine, pingsan, diare, rasa tertekan, mual dan sakit perut. Dismenorea berat terdapat pada skala nyeri dengan tingkatan 7-10. ${ }^{7}$

Terdapat beberapa cara dalam menangani dismenorea, untuk membantu mengurangi rasa nyeri menstruasi dapat dilakukan dengan cara non farmakologi dan farmakologi, yaitu: 
a. Non farmakologi

Pengompresan dengan air hangat, ketika nyeri menstruasi datang, lakukan pengompresan menggunakan air hangat di perut bagian bawah karena dapat membantu merilekskan otot-otot dan sistem saraf. Selain itu mandi air hangat dan mengolesi bagian yang nyeri dengan balsem atau lotion penghangat dapat juga dilakukan untuk menurunkan nyeri. ${ }^{12}$

Melakukan posisi knee chest, yaitu menelungkupkan badan di tempat yang datar, lutut ditekuk dan di dekatkan ke dada. Posisi knee chest dapat menggerakan otot, maka otot menjadi lebih kuat dan elastic secara alami sehingga melenturkan otot-otot pada pelvis dan membantu kelancaran peredaran darah maka meningkatkan relaksasi otot dan menurunkan nyeri ${ }^{13}$ Melakukan olah raga cukup dan teratur seperti joging, lari dan senam serta menyediakan waktu yang cukup untuk beristirahat atau tidur. Olah raga yang cukup dan teratur dapat meningkatkan kadar hormon endorfin yang berperan sebagai natural pain killer. ${ }^{12}$

Distraksi merupakan metode yang digunakan untuk mengalihkan perhatian seseorang terhadap sensasi nyeri. Metode distraksi digunakan untuk nyeri ringan sampai sedang. Akan tetapi, dengan konsentrasi penuh dapat juga digunakan untuk nyeri akut. Pada sebagian kasus, nyeri hanya berkurang pada saat distraksi dilakukan. Jika distraksi telah selesai, klien akan sadar kembaliterhadap rasa nyeri yang dialami. ${ }^{14}$

Teknik imagery guided merupakan pengalaman sensori buatan yang dapat menurunkan persepsi nyeri secara efektif dan menurunkan reaksi terhadap nyeri. Teknik ini dapat dilakukan dengan membayangkan pengalaman yang menyenangkan dari memori, mimpi, fantasi dan penglihatan, dengan berfokus kepada pengalaman yang dibayangkan, klien dapat mengubah persepsinya terhadap nyeri yang dialami. ${ }^{13}$

Pemijatan dapat meminimalkan reaksi terhadap nyeri. Pemijatan merupakan bentukaplikasisentuhandanpergerakan terhadap otot, tendon, dan ligamen tanpa memanipulasi sendi. Tidak hanya menghalangi persepsi rangsang nyeri tetapi juga merelaksasikan kontraksi dan spasme otot karenadapat memperlancar sirkulasi darah. ${ }^{14}$

Teknik relaksasi napas dalam yaitu menarik nafas dalam dari hidungdan perlahan-lahan udara dihembuskan melalui mulut. Hal ini dapatmeningkatkan oksigenasi darah, menurunkan intensitas nyeri dan menurunkan kecemasan. ${ }^{14}$

b. Farmakologi

Untuk mengatasi dismenorea biasanya menggunakan obat-obat sejenis prostaglandin inhibitor yaitu dengan NSAID (Non Steroidal Antiinflammatory Drugs) yang menghambat produksi dan kerja prostaglandin. Untuk kram yang berat, pemberian NSAID seperti naproksen atau piroksikan dapat membantu (Wikjosastro, 1999). Contoh 
obat dari golongan NSAID antara lain aspirin, ibuprofen, naproxen sodium, dan ketoprofen. ${ }^{15}$

\section{BAHAN DAN METODE}

Penelitian ini merupakan penelitian yang menggunakan desain penelitian analitik. Penelitian ini dilakukan dengan melihat hasil kuisioner yang deberikan pada Mahasiswi FK-UMI Makassar Angkatan 2013 yang merupakan objek utama dalam penelitian ini. Adapun data yang diperoleh dari hasil kuisioner kemudian kami gunakan sebagai bahan utama dalam melihat tingkat pengetahuan Mahasiswi FK-UMI Makassar Angkatan 2013 tentang dismenorea dengan perilaku penanganan dismenorea.

Penelitian ini akan dilakukan di Fakultas Kedokteran UMI Makassar. Waktu penelitian adalah bulan Maret sampai Oktober 2015. Populasi pada penelitian ini adalah semua mahasiswi angkatan 2013 Fakultas Kedokteran UMI Makasssar yang masih terdaftar pada saat penelitian dilaksanakan. Penelitian ini menggunakan teknik simple random sampling atau semua populasi yang memenuhi kriteria inklusi yang berjumlah 96 orang. Metode pengumpulan data dilakukan dengan dua cara, yakni menggunakan data primer dan data sekunder. Data primer adalah data yang diperoleh langsung dari responden dimana pengumpulan data dilakukan dengan metode angket yang dibagikan kepada responden untuk mendapatkan jawaban pertanyaan. Sedangkan data sekunder adalah data yang didapatkan dari pihak fakultas yang berhubungan dengan jumlah mahasiswi di fakultas kedokteran UMI Makassar angkatan 2013.

\section{HASIL PENELITIAN}

Berdasarkan penelitian yang telah dilakukan pada seluruh responden yang berjumlah 96 orang, semua pernah mengalami dismenore baik sebelum, selama ataupun setelah menstruasi.

Tabel 1. Distribusi Frekuensi Derajat Dismenorea

\begin{tabular}{lcc}
\hline \hline Derajat dismenorea & Frekuensi & Persentase (\%) \\
\hline Ringan & 64 & 66,67 \\
Sedang & 27 & 28,12 \\
Berat & 5 & 5,21 \\
\hline Jumlah & $\mathbf{9 6}$ & $\mathbf{1 0 0}$ \\
\hline \hline
\end{tabular}

Sumber: Data primer 2015

Pada tabel 1. dapat dilihat bahwa dismenorea sedang sebanyak 27 responden sebagian besar responden mengalami dismenorea ringan, yaitu 64 responden $(28,12 \%)$, dan hanya terdapat 5 responden (66,67\%). Mahasiswi yang mengalami $(5,21 \%)$ yang mengalami dismenorea ringan. 
Tabel 2. Distribusi Frekuensi Karakteristik Usia Responden

\begin{tabular}{lcc}
\hline Usia Responden (tahun) & Frekuensi & Persentase (\%) \\
\hline 17 & 2 & 2,083 \\
18 & 1 & 1,042 \\
19 & 33 & 34,375 \\
20 & 54 & 56,25 \\
21 & 5 & 5,208 \\
22 & 1 & 1,042 \\
\hline Jumlah & $\mathbf{9 6}$ & $\mathbf{1 0 0}$ \\
\hline
\end{tabular}

Sumber: Data primer 2015

Pada tabel 2. dapat dilihat bahwajumlah adalah responden yang berusia 18 tahun dan responden penelitian yang paling banyak 22 tahun, yaitu masing-masing sebanyak 1 adalah responden yang berusia 20 tahun, mahasiswi (1,042\%) dari 96 orang jumlah yaitu sebanyak 54 mahasiswi $(56,25 \%)$ total responden. dan jumlah responden yang paling sedikit

Tabel 3. Tingkat Pengetahuan tentang Dismenorea

\begin{tabular}{lcc}
\hline \hline Kategori Tingkat Pengetahuan & Frekuensi & Persentase (\%) \\
\hline Baik & 33 & 34,4 \\
Cukup & 31 & 32,3 \\
Kurang & 32 & 33,3 \\
\hline Jumlah & $\mathbf{9 6}$ & $\mathbf{1 0 0}$ \\
\hline \hline
\end{tabular}

Sumber: Data primer 2015

Pada tabel 3. dapat dilihat bahwa sebagian besar responden memiliki pengetahuan tentang dismenorea dengan kategori baik, yaitu 33 responden $(34,4 \%)$ dengan kategori cukup 31 responden (32,3\%) dan terdapat 32 responden (33,3\%) dengan kategori tingkat pengetahuan kurang dari total responden 96 mahasiswi.

Tabel 4. Kategori Perilaku Penanganan Dismenorea

\begin{tabular}{lcc}
\hline \hline Bentuk Perilaku & Frekuensi & Persentase (\%) \\
\hline Melakukanteknikdistraksi, relaksasi, atau guildedimaginary & 65 & 18,414 \\
Kompres air hangat & 39 & 11,048 \\
Mengoleskan balsam/ lotion penghangat & 48 & 13,6 \\
Pemijatan & 75 & 21,246 \\
Posisi knee-chest & 49 & 13,881 \\
Olahraga & 37 & 10,48 \\
Mengonsumsi obat anlgetik atau ramuan herbal & 40 & 11,331 \\
\hline Jumlah & $\mathbf{3 5 3}$ & $\mathbf{1 0 0}$ \\
\hline
\end{tabular}

Sumber: Data primer 2015 
Pada tabel 4. diketahui bahwa sebagian besar mahasiswi menangani dismenorea dengan melakukan pemijatan pada daerah yang nyeri, yaitu sebanyak 75 responden
$(21,246 \%)$, dan paling sedikit menangani dismenorea dengan melakukan olahraga yaitu sebanyak 37 responden $(10,48 \%)$.

Tabel 5 Kategori Perilaku Penanganan Dismenorea

\begin{tabular}{lcc}
\hline \hline Kategori Perilaku & Frekuensi & Persentase (\%) \\
\hline Sesuai & 63 & 65,6 \\
Tidak Sesuai & 33 & 34,4 \\
\hline Jumlah & $\mathbf{9 6}$ & $\mathbf{1 0 0}$ \\
\hline \hline
\end{tabular}

Sumber: Data primer 2015

Pada tabel 5. dapat dilihat bahwa sebanyak 63 responden $(65,6 \%)$ memiliki perilaku penanganan dismenorea dengan kategori sesuai, sedangkan 33 responden (34,4 \%) memiliki perilaku penanganan dismenorea dengan kategori tidak sesuai.

Tabel 6. Hubungan tingkat pengetahuan dismenorea dengan perilaku penanganan dismenorea

\begin{tabular}{|c|c|c|c|c|c|c|}
\hline \multirow{3}{*}{$\begin{array}{l}\text { Tingkat Pengetahuan } \\
\text { Dismenorea }\end{array}$} & \multicolumn{4}{|c|}{ Perilaku Penanganan Dismenorea } & \multirow{2}{*}{\multicolumn{2}{|c|}{ Total }} \\
\hline & \multicolumn{2}{|c|}{ Sesuai } & \multicolumn{2}{|c|}{ Tidak Sesuai } & & \\
\hline & $\mathrm{F}$ & $\%$ & $\mathbf{F}$ & $\%$ & $\mathbf{F}$ & $\%$ \\
\hline$\overline{\overline{\text { Baik }}}$ & 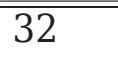 & $3 \overline{33,3}$ & 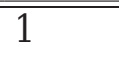 & 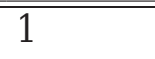 & "33 & 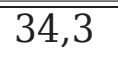 \\
\hline Cukup & 13 & 13,5 & 18 & 18,8 & 31 & 32.3 \\
\hline Kurang & 18 & 18,8 & 14 & 14,6 & 32 & 33,4 \\
\hline Total & 63 & 65,6 & 33 & 34,4 & 96 & 100 \\
\hline
\end{tabular}

Sumber: Data primer 2015, chi-square, $p=0,000(P<0,05)$

Tabel 6. Menunjukkan bahwa sebagian besar responden memiliki tingkat pengetahuan tentang dismenorea dalam kategori baik dengan perilaku penanganan dismenorea yang sesuai, yaitu 32 responden $(33,3 \%)$, sedangkan responden yang memiliki tingkat pengetahuan cukup dengan perilaku penanganan yang sesuai yaitu 13 responden (13,5\%). Pada responden yang memiliki tingkat pengetahuan tentang dismenorea dalam kategori cukup dengan perilaku penanganan dismenorea yang tidak sesuai, yaitu 18 responden(18,8\%). Serta kategori tingkat pengetahuan tentang dismenorea yang kurang dengan perilaku penanganan disemnorea yang sesuai, yaitu 18 responden $(18,8 \%)$ dan tingkat pengetahuan tentang dismenorea yang kurang dengan perilaku penanganan dismenorea yang tidak sesuai, yaitu 14 responden $(14,6 \%)$.

\section{PEMBAHASAN}

Tingkat Pengetahuan tentang Dismenorea

Berdasarkan penelitian yang telah dilakukan pada mahasiswi Fakultas Kedokteran Universitas Muslim Indonesia angkatan 2013, didapatkan hasil bahwa tingkat pengetahuan mahasiswi mengenai dismenorea berada pada kategori baik. Kondisi tersebut terlihat pada tabel 5.3 sebanyak 33 responden (34,4\%) memiliki tingkat pengetahuan yang baik mengenai dismenorea dan sebanyak 31 responden (32,3\%) yang memiliki kategori cukup 
sedangkan sebanyak 32 responden (33,3\%) memiliki kategorikurang.

Pada mahasiswi dengan kategori baik padatingkatpengetahuantentangdismenorea, mahasiswi mampu mengetahui, memahami, mengaplikasi, menganalisis, mensintesis dan mengevaluasi mengenai pengertian, klasifikasi, penyebab dan penanganan dismenorea. Hal itu sesuai dengan teori yang dikemukakan oleh Notoatmodjo (2007), bahwa pengetahuan merupakan hasil dari tahu untuk terbentuknya tindakan seseorang yang mencakup kemampuan kognitif, afektif dan psikomotorik. Pengetahuan yang dilihat dari kemampuan kognitif sesorang mencakup kemampuan untuk mengetahui, memahami, mengaplikasi, menganalisis, mensisntesis dan mengevaluasi suatuhal.

Adabeberapafaktoryangmempengaruhi tingkat pengetahuan mahasiswi Fakultas Kedokteran Universitas Muslim Indonesia Angkatan 2013 mengenai dismenorea, yaitu usia, tingkat pendidikan dan sumber informasi.

Berikut ini adalah faktor yang mempengaruhi tingkat pengetahuan tentang dismenorea pada mahasiswi Fakultas Kedokteran Universitas Muslim Indonesia Angkatan 2013:

Sebagian besar responden pada penelitian ini berusia 20 tahun, yaitu sebanyak 54 responden $(56,25 \%)$ dan usia 19 tahun sebanyak 33 responden (34,375\%) dengan ketegori tingkat pengetahuan tentang dismenorea yang baik. Pada keadaan tersebut terlihat bahwa, semakin bertambah usia mahasiswi, maka tingkat pengetahuan yang dimilikinya akan semakin baik. Dengan pengetahuan tentang dismenorea, mahasiswi Fakultas Kedokteran Universitas Muslim Indonesia Angkatan 2013 dapat mengembangkan kemampuan mengambil keputusan untuk menangani dismenorea yang merupakan manifestasi dari keterpaduan menalar secara ilmiah dan etik yang bertolak dari dismenorea sebagai masalah nyata yang dialami oleh para mahasiswi.

Haltersebut sesuaidenganteori Meliono Irmayanti (2007) yang menyatakan bahwa usia mempengaruhi tingkat pengetahuan seseorang. Dengan usia yang lebih banyak, maka pengalaman yang dimiliki juga akan semakin banyak dan beragam. Pengalaman dapat dijadikan cara untuk menambah pengetahuan seseorang tentang suatu hal. Selain itu usia juga akan mempengaruhi daya tangkap dan pola pikir seseorang. Semakin bertambah usia akan semakin berkembang pula daya tangkap dan pola pikirnya, sehingga pengetahuan yang diperolehnya semakin baik.

Responden yang digunakan dalam penelitian ini berasal dari latar belakang tingkat pendidikan yang sama, yaitu mahasiswi S1 Semester 4 Fakultas Kedokteran Universitas Muslim Indonesia.

Tingkat pendidikan mahasiswi ini mempengaruhi tingkat pengetahuannya tentang dismenorea, sebab seperti yang disampaikan oleh Meliono Irmayanti (2007), makin tinggi tingkat pendidikan maka, makin mudah seseorang mendapatkan pengetahuan karena tingkat pendidikan akan mempengaruhi seseorang untuk menerima ide dan teknologi atau informasi baru.

\section{Perilaku Penanganan Dismenorea}

Perilaku kesehatan menurut Notoatmodjo (2007) adalah bentuk respon 
seseorang terhadap stimulus yang berkaitan dengan sakit, penyakit, sistem pelayanan kesehatan, makanan serta lingkungan. Dari pernyataan yang dikemukakan oleh Notoatmodjo tersebut, yang dimaksud dengan perilaku penanganan dismenorea adalah bentuk respon seseorang terhadap keluhan dismenorea yang dirasakannya untuk menangani keluhan tersebut.

Beragam cara penanganan dismenorea telah dilakukan oleh sebagian besar mahasiswi. Dari hasil wawancara dengan responden, penanganan dismenorea dilakukan untuk mengurangi rasanya nyeri agar tidak semakin parah sehingga tidak mengganggu aktifitas keseharian mereka. Hal tersebut sesuai dengan pendapat Kartono (2006), bahwa penanganan yang kurang tepat membuat dewasa muda selalu mengalaminya setiap siklus menstruasinya.

Berdasarkan hasil penelitian, seluruh mahasiswi Fakultas Kedokteran Universitas Muslim Indonesia Angkatan 2013 telah melakukan perilaku penanganan dismenorea. Perilaku penanganan dismenorea didasarkan oleh cara berfikir dan bersikap positif tentang keluhan dismenorea yang dialaminya, sehingga terbentuk perilaku berupa pemberian kompres hangat, olah raga teratur dan istirahat, pengkonsumsian makanan bergizi, pengkonsumsian obat analgetik. Hal itu sesuai pendapat Wiknjosastro (2007) bahwa, untuk menurunkan angka kejadian dismenorea dan mencegah keadaan dismenorea tidak bertambah berat, beberapa usaha dapat dilakukan seperti penerangan dan nasihat, pemberian obat analgesik, pola hidup sehat, terapi hormonal dan terapi obat nonsteroid antiprostaglandin sesuai dengan petunjuk dokter.
Pada tabel 5.4, diperlihatkan bahwa sebagian besar mahasiswi, yaitu sebanyak 75 responden $(21,246 \%)$ melakukan pemijatan untuk menangani dismenorea yang dirasakan secara mandiri. Pemijatan tersebut dilakukan di daerah yang dirasakan nyeri, yaitu daerah perut bagian bawah. Hal ini sesuai dengan pendapat Suzanne S. (2002) bahwa pemijatan dapat meminimalkan reaksi terhadap nyeri, sebab selain menghalangi persepsi rangsang nyeri, pemijatan juga merelaksasikan kontraksi dan spasme otot karena dapat memperlancar sirkulasi darah.

Pada tabel 5.5, diketahui bahwa sebanyak 63 responden (65,6\%) telah melakukan perilaku yang sesuai untuk menangani dismenorea. Perilaku yang sesuai tersebut ditunjukkan dari kesadaran mahasiswi untuk selalu memperhatikan rasa nyeri yang dirasakannya ketika menstruasi. Dari kesadaran mahasiswi, muncullah rasa ketertarikan untuk mengetahui penyebab dan tindakan yang dapat dilakukan untuk menangani keluhan dismenorea yang mereka rasakan sehingga pada akhirnya mereka dapat menerima kondisi tersebut. Seperti yang diungkapkan Notoatmodjo (2007) bahwa perilaku penanganan dismenorea yang dilakukan terbentuk karena adanya suatu proses tahapan awareness (kesadaran), interest (merasa senang), evaluation (menimbang-nimbang), trial (mencoba), adaptation (menerima) pada diri seseorang.

\section{Hubungan Tingkat Pengetahuan tentang Dismenorea dengan Perilaku Penanganan Dismenorea}

Hasil penelitian menunjukkan bahwa terdapat hubungan antara tingkat pengetahuan tentang dismenorea dengan 
perilaku penanganan dismenorea pada mahasiswi Fakultas Kedokteran Universitas Muslim Indonesia Angkatan 2013. Sebanyak 32 responden $(33,3 \%)$ memiliki tingkat pengetahuan baik dan berperilaku baik dalam menangani dismenorea. Sehingga dapat disimpulkan bahwa ada hubungan tingkat pengetahuan tentang dismenorea dengan perilaku penanganan dismenorea pada mahasiswi Fakultas Kedokteran Universitas Muslim Indonesia Angkatan 2013.

Apabila melihat adanya hubungan tingkat pengetahuan tentang dismenorea dengan perilaku penanganan dismenorea pada mahasiwi Fakultas Kedokteran Universitas Muslim Indonesia Angkatan 2013, maka dapat disimpulkan bahwa semakin baik tingkat pengetahuan yang dimiliki maka semakin baik perilaku yang dilakukan untuk menanganinya. Hal ini sesuai dengan hasil penelitian Rani (2013) yang berjudul Pengaruh Pengetahuan dengan penanganan Sindroma Pra Haid pada Remaja Putri Kelurahan Notoprajan Yogyakarta.

Semakin baik pengetahuan tentang dismenorea yang dimiliki mahasiswi, maka perilaku yang ditunjukkan untuk menangani dismenorea juga semakin baik. Dengan pengetahuan yang baik akan mempengaruhi sikapmahasiswiuntukmenanganidismenorea yangtepat.MenurutAzwar(2003), haltersebut karena pengetahuan seseorang tentang sesuatu hal akan mempengaruhi sikapnya. Sikap positif maupun negative tergantung dari pemahaman individu tentang suatu hal tersebut, sehingga sikap ini selanjutnya akan mendorong individu melakukan perilaku tertentu pada saat dibutuhkan, tetapi kalau sikapnya negative, justru akan menghindari untuk melakukan perilaku tersebut.

\section{DAFTAR PUSTAKA}

1. Badziad, A. 2003. Endokrinologi dan Ginekologi. Edisi ke-2. Jakarta: Media Aesculapius Fakultas Kedokteran Universitas.

2. Proverawati, A., Misaroh, S. 2009. Menarche; Pertama Penuh Makna. Bandung: Nuha Medika

3. Admin. 2005. Menstruasi dan Penanganan Dismenorea. Cermin Dunia Kedokteran. No 133/ 2005.

4. Warner,P., Gritchley, H.O,dkk. 2001. Referral for Menstrual Problems: Cross Sectional Survey of Symptoms, Reason for Referral, and Management; Vol 323. UK. British Medical Journal.

5. Fritz, M.A., Speroff, L., 2011. Chapter 14 Menstrual Disorder; Dymenorrhea. Clinical Gynecologic Endocrinology and Infertility. USA

6. Morgan, G., Hamilton, C., 2009. Obstetri \& Ginekologi Panduan Praktik Edisi 2. Jakarta: Penerbit Buku Kedokteran EGC

7. Manuaba, I.G.B. 2001. Kapita Selekta Pelaksanaan Rutin Obstetri Ginekologi dan KB. Jakarta: Penerbit Buku Kedokteran EGC

8. Dang, D.K., dkk. 2010. Women's Health Across the Lifespan: A Pharmacotherapeutic Approach. USA

9. Vuong. L,K. 2006. Textbook of Therapeutics: Drug and Disease Management $8^{\text {th }}$ Edition. USA. Lippincott Williams \& Wilkins

10. Ostrzenski, A. 2002. Gynecology; Integrating Coventional, Complementary and Natural Alternative Therapy. USA. Lippincott Williams \& Wilkins 
11. Rothblatt, A.B. 2004. Current Care of Women Diagnosis \& Treatment. USA. The McGraw HillLange.

12. Taruna. 2003. Hipoterapi.Diperoleh dari: http://www.medikaholistik.com/ [Diakses pada 4 Juni 2014]

13. Akatri, S. 1996. Penuntun Hidup Sehat Menurut Ilmu Kesehatan Modern. Surabaya: Airlangga University Press.

14. Smeltzer, Suzanne. 2002. Buku Ajar Medikal Bedah Edisi Kedelapan. Jakarta: EGC.

15. Tamsuri, A. 2007. Konsep dan Penatalaksanaan Nyeri.Jakarta: EGC.

16. Wikinjosastro, Hanifa. 1999. Ilmu Kandungan. Jakarta: Yayasan Bina Pustaka Sarwono Prawirohardjo.

17. Sulastri. 2006. Tesis: Perilaku Pencarian Pengobatan Keluhan Dysmenorherrea pada Remaja di Kabupaten Purworejo Prinsi Jawa Tengah. Yogyakarta: Universitas Gajah Mada. Diperoleh dari: http://digilib.ugm.ac.id. [Diakses pada 4 Juni 2014]
18. Gregory Garra DO, Adam J. Singer MD, dkk. 2009. ValiditionofWong-BakerFaces Pain Ratig Scale. Diperolehdari: http:// onlinelibrary.wiley.com/doi/10.1111/ j.1553-2712.2009.00620.x/full. [Diaksespada 4 Juni 2014]

19. Notoatmodjo. 2007. Promosi Kesehatan dan Ilmu Prelaku.Jakarta: Rineka Cipta.

20. Arikunto, S., 2007.Manajemen Penelitian. Jakarta: Rineka Cipta

21. Arif. 2011. Alur Penelitian. Diperoleh dari: $\quad$ http://www.scribd.com. doc196293699 secondary-surveypemeriksaan-penunjang-dan-evaluasi. html. [Diakses pada 4 Juni 2014] Wiknjosastro, H. 2007. Ilmu Kandungan. Jakarta: Pustaka Sarwon Prwirohardjo. 